\title{
Basket trial of TRK inhibitors demonstrates efficacy in TRK fusion-positive cancers
}

\author{
Yu Chen ${ }^{1,2,3}$ and Ping Chi ${ }^{1,2,3^{*}}$
}

\begin{abstract}
Unlike many conventional cancers with preferential patterns of oncogenic genetic alterations, TRK fusions resulting from NTRK $1 / 2 / 3$ genetic alterations drive oncogenic transformations in more than 20 different malignancies over diverse tissue/cell lineages, in both children and adults. A recent "basket" study of larotrectinib, a TRK inhibitor, has demonstrated significant efficacy in TRK fusion-positive tumors of all types from infants to the elderly. Here, we discuss the larotrectinib study and perspectives and challenges in developing "tumor-agnostic" targeted therapies in rare tumors.
\end{abstract}

\section{Background}

Traditionally, cancers are classified and treated based on their pathologic classification and tissue of origin. Advances in sequencing technology and large-scale cancer genomics effort (e.g., the International Cancer Genome Consortium and The Cancer Genome Atlas (TCGA) have identified many targetable driver genetic alterations across different tumor types and have shifted the cancer sub-classification based on driver genetic alterations. For example, lung adenocarcinomas are further sub-classified by KRAS and EGFR mutations and ALK and ROS1 translocation. Most "driver" genetic alterations are preferentially found in certain cell/tissue lineages. For example, the $B R A F^{\mathrm{V} 600}$ mutation occurs at high frequencies in specific tumor types, e.g., melanoma, thyroid cancer, hairy cell leukemia, Langerhans cell histiocytosis, and colorectal cancer, and at significantly lower frequencies in other tissue lineages. The responses to $B R A F^{\mathrm{V} 600}$-targeted therapies are not uniform, with some cancer types (e.g., colorectal cancer) exhibit tissue lineage-specific primary resistance [1-3], underlining the importance of the tissue lineage-specific cellular context.

\footnotetext{
* Correspondence: chip@mskcc.org

'Human Oncology and Pathogenesis Program, Memorial Sloan Kettering Cancer Center, New York, NY 10065, USA

${ }^{2}$ Department of Medicine, Memorial Sloan Kettering Cancer Center, New York, USA

Full list of author information is available at the end of the article
}

\section{TRK fusions are rare but drive oncogenesis in diverse tissue lineages}

The NTRK1, NTRK2, and NTRK3 genes, encoding the tropomyosin receptor kinases (TRK), TRKA, TRKB, and TRKC, respectively, are receptor tyrosine kinases that are normally expressed in the nervous system [4]. Physiologically, TRK receptor tyrosine kinases are activated by binding of mature neurotrophins, which mediate neuronal survival and synaptic plasticity in the central nervous system [4]. NTRK genetic alterations (e.g., translocations) resulting in TRK fusion proteins can lead to ligand-independent activation of TRK kinases and drive oncogenic transformation [5-7]. To date, TRK fusions are found in more than 20 different tumor types. With the exception of several rare tumor types (e.g., secretory breast carcinoma, mammary analog secretory carcinoma, congenital fibrosarcomas, and congenital mesoblastic nephroma), the majority of the TRK fusions occur in low frequencies in a variety of common cancers over a diverse tissue/cell lineages (e.g., lung adenocarcinoma, sarcoma, acute myeloid leukemia, colorectal cancer) [6, 7] (Table 1). The rarity of TRK fusions and the heterogeneity of tumor types present incredible challenges to clinically evaluate TRK inhibitors. Diagnostically, because of large introns, these fusions are difficult to detect using multiplex targeted exome capture panels (e.g., FoundationOne ${ }^{\circ}$, MSK-IMPACT $\left.{ }^{\mathrm{mn}}\right)$. 
Table 1 Rare TRK fusions in diverse tumor types

\begin{tabular}{|c|c|c|}
\hline Tumor type & NTRK1/2/3 involved (frequency) & Detection methods \\
\hline Ph-like acute lymphoblastic leukemia & NTRK3 (1/154) & RNA-seq, whole-genome seq, whole-exome seq [18] \\
\hline Appendiceal adenocarcinoma & NTRK (unspecified) (2/97) & $\begin{array}{l}\text { MALDI-TOF mass spectroscopy genotyping (Sequenom), } \\
\text { targeted NGS (MSK-IMPACT) [19] }\end{array}$ \\
\hline Astrocytoma & NTRK2 (3/96) & RNA-seq, whole-genome seq [20] \\
\hline Breast invasive carcinoma & NTRK3 (1/1072) & RNA-seq (TCGA) [21] \\
\hline Intrahepatic cholangiocarcinoma & NTRK1 $(1 / 28)$ & Targeted NGS [22] \\
\hline \multirow[t]{3}{*}{ Colon adenocarcinoma } & NTRK1 (8/1559) & IHC, RT-PCR [23] \\
\hline & NTRK1 $(1 / 66)$ & IHC, RT-PCR [24] \\
\hline & NTRK3 (2/286) & RNA-seq (TCGA) [21] \\
\hline \multirow[t]{2}{*}{ GIST } & NTRK3 (1/186) & Targeted NGS (Foundation Medicine) [25] \\
\hline & NTRK3 $(1 / 31)$ & RNA-seq, FISH, RT-PCR [26] \\
\hline \multirow[t]{3}{*}{ Glioblastoma } & NTRK1 (1/157) & RNA-seq (TCGA) [21] \\
\hline & NTRK1 (2/185) & RNA-seq (TCGA and other) [27] \\
\hline & NTRK1 (3/115) & Targeted NGS [28] \\
\hline Brain low-grade glioma & NTRK2 (2/461) & RNA-seq (TCGA) [21] \\
\hline \multirow{3}{*}{$\begin{array}{l}\text { Pediatric DIPG and non-brainstem } \\
\text { high-grade glioma }\end{array}$} & NTRK1 (3/127) & RNA-seq, whole-genome seq [29] \\
\hline & NTRK2 (3/127) & RNA-seq, whole-genome seq [29] \\
\hline & NTRK3 (2/127) & RNA-seq, whole-genome seq [29] \\
\hline \multirow[t]{2}{*}{ Head and neck squamous cell carcinoma } & NTRK2 (1/411) & RNA-seq (TCGA) [21] \\
\hline & NTRK3 (1/411) & RNA-seq (TCGA) [21] \\
\hline \multirow[t]{3}{*}{ Congenital mesoblastic nephroma } & NTRK3 (5/6) & RT-PCR, FISH [30] \\
\hline & NTRK3 (10/15) & RT-PCR [31] \\
\hline & NTRK3 (13/19) & FISH [32] \\
\hline \multirow[t]{2}{*}{ Infantile (congenital) fibrosarcoma } & NTRK3 (10/11) & RT-PCR, IHC [33] \\
\hline & NTRK3 (5/5) & RT-PCR, FISH [30] \\
\hline \multirow[t]{2}{*}{ Lung adenocarcinoma } & NTRK1 (3/91) & Targeted NGS (Foundation Medicine), FISH [34] \\
\hline & NTRK2 (1/513) & RNA-seq (TCGA) [21] \\
\hline \multirow[t]{2}{*}{ Breast secretory carcinoma } & NTRK3 (12/13) & RT-PCR, FISH [35] \\
\hline & NTRK3 (9/9) & FISH, targeted NGS [36] \\
\hline \multirow{4}{*}{$\begin{array}{l}\text { Mammary analogue secretory carcinoma } \\
\text { (MASC) of salivary glands }\end{array}$} & NTRK3 (13/14) & RT-PCR, FISH [37] \\
\hline & NTRK3 (15/15) & FISH [38] \\
\hline & NTRK3 (5/6) & FISH, targeted NGS [36] \\
\hline & NTRK3 (16/20) & RT-PCR, FISH [39] \\
\hline Melanoma (skin cutaneous) & NTRK3 (1/374) & RNA-seq (TCGA) [21] \\
\hline Spitz tumors and spitzoid melanoma & NTRK1(23/140) & Targeted NGS(Foundation Medicine), FISH, IHC [40] \\
\hline Sarcoma (NOS) & NTRK1 (1/103) & RNA-seq (TCGA) [21] \\
\hline \multirow[t]{2}{*}{ Uterine sarcoma } & NTRK1 (3/97) & RNA-seq, FISH, IHC, targeted NGS [41] \\
\hline & NTRK3 (1/97) & RNA-seq, FISH, IHC, targeted NGS [41] \\
\hline \multirow[t]{2}{*}{ Thyroid carcinoma } & NTRK1 (5/498) & RNA-seq (TCGA) [21] \\
\hline & NTRK3 (7/498) & RNA-seq (TCGA) [21] \\
\hline \multirow[t]{7}{*}{ Papillary thyroid carcinoma } & NTRK1 (15/119) & RT-PCR [42] \\
\hline & NTRK1 (2/38) & Southern [43] \\
\hline & NTRK1 (pediatric) (1/27) & Targeted NGS [44] \\
\hline & NTRK3(radiation-associated) (2/26) & RNA-seq [45] \\
\hline & NTRK3(radiation-associated) (9/62) & RNA-seq [46] \\
\hline & NTRK3(sporadic) (3/151) & RNA-seq [46] \\
\hline & NTRK3(pediatric) (6/27) & Targeted NGS [44] \\
\hline
\end{tabular}




\section{TRK inhibitor larotrectinib demonstrates efficacy in a basket trial}

Recently, Drilon and colleagues reported a phase I/II clinical trial to evaluate the safety and efficacy of larotrectinib, a highly selective small-molecule inhibitor of all three TRK proteins, using a novel "basket" trial design that enrolled patients based on NTRK genetic alterations regardless of age or tumor types [8]. A total of 55 patients (ages 4 months-76 years old) with 16 different tumor histologies were treated on three protocols, and the results were pooled. The investigators found that larotrectinib was generally well-tolerated with $<5 \%$ treatment-related grade 3 or 4 adverse events. The overall RECIST response rate was $75 \%$ (95\% confidence interval, $61-85)$ by independent review and $80 \%$ (95\% confidence interval, 67-90) by investigator assessment. At 1 year, $71 \%$ of patients are with ongoing responses and $55 \%$ of patients remain progression-free. The median duration of response and progression-free survival has not been reached after 8.3 and 9.9 months of median follow-up, respectively. Importantly, responses were observed in nearly all tumor types and age groups. Three of the six patients who did not response to larotrectinib (primary resistance) had undetectable TRK proteins by immunohistochemistry (IHC) despite molecularly identified TRK fusion at a screening in local laboratories. In the ten patients who progressed after an initial response for at least 6 months, nine had identifiable secondary resistant mutations in NTRK1 or NTRK3, including substitutions in the solvent front position (NTRK1 G595R or NTRK3 G623R), gatekeeper mutation (NRTK1 F589 L), and the xDFG position NTRK1 G667S or NTRK3 G696A). The acquired resistance mechanisms have been described for other oncogenic kinase-targeted therapies [9-11]. The next generation of TRK inhibitors is in development to overcome the acquired resistance in TRK $[7,12]$ (see Table 2).

\section{Future perspectives}

The study by Drillon et al. [8] comes on the heels of several basket trials, including the AKT inhibitor AZD5363 in AKT1 E17K-mutant tumors [13], the PD1 inhibitor pembrolizumab in mismatch repair deficient tumors [14], and the pan-HER kinase inhibitor neratinib in HER2- and HER3-mutant tumors [15], with variable clinical success. This current study provides a compelling case for tumor-agnostic, molecular-driven "basket" approaches for clinical investigations of rare driver mutations across diverse tumor types. It paves a clinical pathway to effective therapeutics for patients with rare tumors and rare driver mutations. In addition to larotrectinib, there is a variety of TRK inhibitors currently in clinical development (Table 1), including next-generation TRK inhibitors that can overcome acquired resistance (e.g., LOXO-195, TPX-0005).

Despite the early clinical success with new generations of TRK inhibitors and novel trial design, the challenges remain for real-time identification of rare TRK fusions. What would be the ideal diagnostics methodology? DNA-based next-generation sequencing (NGS) assays have relatively high false-negative and false-positive rate and do not identify novel fusions. RNA-based NGS assays (e.g., Archer Dx) can detect novel fusions and has reasonable sensitivity. However, both DNA- and RNA-based NGS assays can be costly and effort intensive. Alternatively, IHC of TRK is a sensitive and efficient method for identification of TRK expression $[16,17]$. Nevertheless, it would not readily discriminate TRK fusion arising through genetic alterations where

Table 2 TRK inhibitors currently in clinical development

\begin{tabular}{|c|c|c|c|c|}
\hline Drug name & Targets & $\begin{array}{l}\text { Development } \\
\text { stage }\end{array}$ & $\begin{array}{l}\text { Clinical trial } \\
\text { identifier }\end{array}$ & Company \\
\hline LOXO-101 (larotrectinib) & NTRK1/2/3 & Phase II & $\begin{array}{l}\text { NCT02122913 } \\
\text { NCT02637687 } \\
\text { NCT02576431 } \\
\text { NCT03213704 }\end{array}$ & Loxo Oncology \\
\hline LOXO-195 & NTRK1/2/3 (resistant) & Phase $1 / \|$ & NCT03215511 & Loxo Oncology \\
\hline RXDX-101 (entrectinib) & NTRK1/2/3, ALK, ROS1 & $\begin{array}{l}\text { Phase I/II, } \\
\text { Phase II, } \\
\text { Phase I/lb }\end{array}$ & $\begin{array}{l}\text { NCT02097810 } \\
\text { NCT02568267 } \\
\text { NCT02650401 }\end{array}$ & Ignyta \\
\hline TPX-0005 (ropotrectinib) & $\begin{array}{l}\text { NTRK1/2/3, ALK, ROS1 (resistant), JAK2, SRC, } \\
\text { DDR1, FAK }\end{array}$ & Phase $1 / \|$ & NCT03093116 & TP Therapeutics \\
\hline LY2801653 (merestinib) & $\begin{array}{l}\text { NTRK1/2/3, MET, MST1R, FLT3, AXL, MERTK, TEK, } \\
\text { ROS1, DDR1/2, MKNK1/2 }\end{array}$ & Phase II & NCT02920996 & Eli Lilly and Company \\
\hline DS-6051b & NTRK1/2/3, ROS1 & Phase I & $\begin{array}{l}\text { NCT02675491 } \\
\text { NCT02279433 }\end{array}$ & Daiichi Sankyo \\
\hline PLX7486 & NTRK1/2/3, CSF1R & Phase I & NCT01804530 & Plexxikon/Daiichi Sankyo \\
\hline MGCD516 (sitravatinib) & NTRK1/2/3, MET, KIT, PDGFRA, KDR, DDR2, RET, CBL & Phase $\mid / / b$ & NCT02219711 & Mirati Therapeutics \\
\hline
\end{tabular}


TRK inhibitors can be highly effective from full-length TRK expression in tumors inherited through development where the functional significance of TRK expression and clinically impact is unknown. TRK IHC can also be associated with false positives in certain tissue and tumor types. Furthermore, unlike NGS-based assays, IHC cannot be easily multiplexed into a panel without added cost and effort. While TRK IHC can be easily justified for high-prevalence tumors (e.g., congenital fibrosarcoma or secretory breast carcinoma), its role in low-prevalence common tumors such as colorectal cancer becomes more debatable. Importantly, it is unclear which diagnostic modality, NGS of NTRK alterations or IHC of TRK expression, is more predictive of response to TRK inhibitors. In the NEJM by Drilon et al., three out of the six non-responders to larotrectinib did not have centrally confirmed TRK expression by pan-TRK IHC, despite the detection of NTRK rearrangement by NGS in the local laboratory [8]. This observation suggests that TRK expression by IHC may be necessary for response. Currently, Pan-TRK IHC and Illumina NGS (RNA and DNA assays in one design) are both being developed as companion diagnostics to larotrectinib and other TRK inhibitors.

With a shifting paradigm of identifying genetic alterations in a tumor-agnostic manner, the development of a single assay that can identify multiple types of actionable genetic alterations would be paramount. In the meantime, TRK IHC would be a reasonable initial diagnostics for rare tumors where TRK fusions are frequent, and possibly common tumors where driver mutations are absent.

\section{Funding}

This work was supported by grants from the NIH/NCI (R01CA193837, YC; R01CA208100, YC; P50CA092629, YC; U54CA224079, YC; P50CA140146, PC; DP2 CA174499, PC; R01CA228216, PC), FDA/OPD (R01FD005731, PC), US DOD (W81XWH-10-1-0197, PC), Prostate Cancer Foundation (YC), and Bloomberg Family Foundation (NTAP Collins Scholar, PC).

Availability of data and materials

All supporting data and materials have been included within the article.

\section{Authors' contributions}

Both authors wrote, revised, and approved the final manuscript.

\section{Ethics approval and consent to participate}

Not applicable.

\section{Competing interests}

Both authors declare that they have no competing interests.

\section{Author details}

'Human Oncology and Pathogenesis Program, Memorial Sloan Kettering Cancer Center, New York, NY 10065, USA. ²Department of Medicine, Memorial Sloan Kettering Cancer Center, New York, USA. ${ }^{3}$ Department of Medicine, Weill Cornell Medical College, New York, USA.
Received: 20 March 2018 Accepted: 29 May 2018

Published online: 07 June 2018

\section{References}

1. Hyman DM, Puzanov I, Subbiah V, et al. Vemurafenib in multiple nonmelanoma cancers with BRAF V600 mutations. N Engl J Med. 2015;373: 726-36.

2. Prahallad A, Sun $C$, Huang $S$, et al. Unresponsiveness of colon cancer to BRAF(V600E) inhibition through feedback activation of EGFR. Nature. 2012; 483:100-3.

3. Corcoran RB, Ebi H, Turke AB, et al. EGFR-mediated re-activation of MAPK signaling contributes to insensitivity of BRAF mutant colorectal cancers to RAF inhibition with vemurafenib. Cancer Discovery. 2012;2:227-35.

4. Chao MV. Neurotrophins and their receptors: a convergence point for many signalling pathways. Nat Rev Neurosci. 2003:4:299-309.

5. Martin-Zanca D, Hughes SH, Barbacid M. A human oncogene formed by the fusion of truncated tropomyosin and protein tyrosine kinase sequences. Nature. 1986;319:743-8.

6. Vaishnavi A, Le AT, Doebele RC. TRKing down an old oncogene in a new era of targeted therapy. Cancer Discovery. 2015;5:25-34.

7. Amatu A, Sartore-Bianchi A, Siena S. NTRK gene fusions as novel targets of cancer therapy across multiple tumour types. ESMO Open. 2016;1:e000023.

8. Drilon A, Laetsch TW, Kummar S, et al. Efficacy of larotrectinib in TRK fusionpositive cancers in adults and children. N Engl J Med. 2018;378:731-9.

9. Katayama R, Shaw AT, Khan TM, et al. Mechanisms of acquired crizotinib resistance in ALK-rearranged lung cancers. Sci Transl Med. 2012:4:120ra17.

10. Kobayashi S, Boggon TJ, Dayaram T, et al. EGFR mutation and resistance of non-small-cell lung cancer to gefitinib. N Engl J Med. 2005;352:786-92.

11. Core LI, Martins AL, Danko CG, Waters CT, Siepel A, Lis JT. Analysis of nascent RNA identifies a unified architecture of initiation regions at mammalian promoters and enhancers. Nat Genet. 2014;46:1311-20.

12. Drilon $A$, Nagasubramanian $R$, Blake JF, et al. A next-generation TRK kinase inhibitor overcomes acquired resistance to prior TRK kinase inhibition in patients with TRK fusion-positive solid tumors. Cancer Discovery. 2017;7: 963-72.

13. Hyman DM, Smyth LM, Donoghue MTA, et al. AKT inhibition in solid tumors with AKT1 mutations. J Clin Oncol. 2017:35:2251-9.

14. Le DT, Durham JN, Smith KN, et al. Mismatch repair deficiency predicts response of solid tumors to PD-1 blockade. Science. 2017;357:409-13.

15. Hyman DM, Piha-Paul SA, Won $\mathrm{H}$, et al. HER kinase inhibition in patients with HER2- and HER3-mutant cancers. Nature. 2018;554:189-94.

16. Hechtman JF, Benayed R, Hyman DM, et al. Pan-Trk immunohistochemistry is an efficient and reliable screen for the detection of NTRK fusions. Am J Surg Pathol. 2017:41:1547-51.

17. Rudzinski ER, Lockwood CM, Stohr BA, et al. Pan-Trk immunohistochemistry identifies NTRK rearrangements in pediatric mesenchymal tumors. Am J Surg Pathol. 2018;

18. Roberts KG, Li Y, Payne-Turner D, et al. Targetable kinase-activating lesions in Ph-like acute lymphoblastic leukemia. N Engl J Med. 2014;371:1005-15.

19. Braghiroli MI, Nash GM, Morris M, et al. Genomic profiling and efficacy of anti-EGFR therapy in appendiceal adenocarcinoma. J Clin Oncol. 2016; 34(Suppl 4S):abstr 574.

20. Jones DT, Hutter B, Jager N, et al. Recurrent somatic alterations of FGFR1 and NTRK2 in pilocytic astrocytoma. Nat Genet. 2013;45:927-32.

21. Stransky N, Cerami E, Schalm S, Kim JL, Lengauer C. The landscape of kinase fusions in cancer. Nat Commun. 2014;5:4846.

22. Ross JS, Wang K, Gay L, et al. New routes to targeted therapy of intrahepatic cholangiocarcinomas revealed by next-generation sequencing. Oncologist. 2014;19:235-42.

23. Creancier L, Vandenberghe I, Gomes B, et al. Chromosomal rearrangements involving the NTRK1 gene in colorectal carcinoma. Cancer Lett. 2015;365: 107-11.

24. Ardini E, Bosotti R, Borgia AL, et al. The TPM3-NTRK1 rearrangement is a recurring event in colorectal carcinoma and is associated with tumor sensitivity to TRKA kinase inhibition. Mol Oncol. 2014;8:1495-507.

25. Shi E, Chmielecki J, Tang CM, et al. FGFR1 and NTRK3 actionable alterations in "wild-type" gastrointestinal stromal tumors. J Transl Med. 2016;14:339.

26. Brenca M, Rossi S, Polano M, et al. Transcriptome sequencing identifies ETV6-NTRK3 as a gene fusion involved in GIST. J Pathol. 2016;238:543-9.

27. Frattini $\mathrm{V}$, Trifonov $\mathrm{V}$, Chan JM, et al. The integrated landscape of driver genomic alterations in glioblastoma. Nat Genet. 2013;45:1141-9. 
28. Zheng Z, Liebers $M$, Zhelyazkova B, et al. Anchored multiplex PCR for targeted next-generation sequencing. Nat Med. 2014;20:1479-84.

29. Wu G, Diaz AK, Paugh BS, et al. The genomic landscape of diffuse intrinsic pontine glioma and pediatric non-brainstem high-grade glioma. Nat Genet. 2014;46:444-50.

30. Rubin BP, Chen CJ, Morgan TW, et al. Congenital mesoblastic nephroma $\mathrm{t}(12 ; 15)$ is associated with ETV6-NTRK3 gene fusion: cytogenetic and molecular relationship to congenital (infantile) fibrosarcoma. Am J Pathol. 1998;153:1451-8.

31. Knezevich SR, Garnett MJ, Pysher TJ, Beckwith JB, Grundy PE, Sorensen PH. ETV6-NTRK3 gene fusions and trisomy 11 establish a histogenetic link between mesoblastic nephroma and congenital fibrosarcoma. Cancer Res. 1998:58:5046-8

32. El Demellawy D, Cundiff CA, Nasr A, et al. Congenital mesoblastic nephroma: a study of 19 cases using immunohistochemistry and ETV6-NTRK3 fusion gene rearrangement. Pathology. 2016;48:47-50.

33. Bourgeois JM, Knezevich SR, Mathers JA, Sorensen PH. Molecular detection of the ETV6-NTRK3 gene fusion differentiates congenital fibrosarcoma from other childhood spindle cell tumors. Am J Surg Pathol. 2000;24:937-46.

34. Vaishnavi A, Capelletti M, Le AT, et al. Oncogenic and drug-sensitive NTRK rearrangements in lung cancer. Nat Med. 2013;19:1469-72.

35. Tognon C, Knezevich SR, Huntsman D, et al. Expression of the ETV6-NTRK3 gene fusion as a primary event in human secretory breast carcinoma. Cancer Cell. 2002;2:367-76.

36. Krings $G$, Joseph NM, Bean GR, et al. Genomic profiling of breast secretory carcinomas reveals distinct genetics from other breast cancers and similarity to mammary analog secretory carcinomas. Mod Pathol. 2017;30:1086-99.

37. Skalova A, Vanecek T, Sima R, et al. Mammary analogue secretory carcinoma of salivary glands, containing the ETV6-NTRK3 fusion gene: a hitherto undescribed salivary gland tumor entity. Am J Surg Pathol. 2010;34:599-608.

38. Bishop JA, Yonescu R, Batista D, Begum S, Eisele DW, Westra WH. Utility of mammaglobin immunohistochemistry as a proxy marker for the ETV6NTRK3 translocation in the diagnosis of salivary mammary analogue secretory carcinoma. Hum Pathol. 2013;44:1982-8.

39. Skalova A, Vanecek T, Simpson RH, et al. Mammary analogue secretory carcinoma of salivary glands: molecular analysis of 25 ETV6 gene rearranged tumors with lack of detection of classical ETV6-NTRK3 fusion transcript by standard RT-PCR: report of 4 cases harboring ETV6-X gene fusion. Am J Surg Pathol. 2016:40:3-13.

40. Wiesner T, He J, Yelensky R, et al. Kinase fusions are frequent in Spitz tumours and spitzoid melanomas. Nat Commun. 2014:5:3116.

41. Chiang S, Cotzia P, Hyman DM, et al. NTRK fusions define a novel uterine sarcoma subtype with features of fibrosarcoma. Am J Surg Pathol. 2018;42: 791-8.

42. Musholt TJ, Musholt PB, Khaladj N, Schulz D, Scheumann GF, Klempnauer J. Prognostic significance of RET and NTRK1 rearrangements in sporadic papillary thyroid carcinoma. Surgery. 2000;128:984-93.

43. Wajjwalku W, Nakamura S, Hasegawa Y, et al. Low frequency of rearrangements of the ret and trk proto-oncogenes in Japanese thyroid papillary carcinomas. Jpn J Cancer Res. 1992:83:671-5.

44. Prasad ML, Vyas M, Horne MJ, et al. NTRK fusion oncogenes in pediatric papillary thyroid carcinoma in northeast United States. Cancer. 2016;122: 1097-107.

45. Ricarte-Filho JC, Li S, Garcia-Rendueles ME, et al. Identification of kinase fusion oncogenes in post-Chernobyl radiation-induced thyroid cancers. Clin Invest. 2013;123:4935-44.

46. Leeman-Neill RJ, Kelly LM, Liu P, et al. ETV6-NTRK3 is a common chromosomal rearrangement in radiation-associated thyroid cancer. Cancer. 2014;120:799-807.

\section{Ready to submit your research? Choose BMC and benefit from:}

- fast, convenient online submission

- thorough peer review by experienced researchers in your field

- rapid publication on acceptance

- support for research data, including large and complex data types

- gold Open Access which fosters wider collaboration and increased citations

- maximum visibility for your research: over $100 \mathrm{M}$ website views per year

At BMC, research is always in progress.

Learn more biomedcentral.com/submissions 